\title{
A RAZOÁVEL DURAÇÃ̃o dO PROCESSO E A ANTECIPAÇÃo DA TUTELA PELA INCONTROVÉRSIA DO PEDIDO - UMA NORMA CONSTITUCIONAL SIMBÓLICA (?)
}

\author{
THE REASONABLE LENGTH OF PROCEEDINGS AND THE ANTECIPATION \\ OF JUDICIAL RESPONSE CONSIDERING INCONTROVERSIAL DEMANDS - \\ A CONSTITUTIONAL SYMBOLIC PROVISION (?)
}

\author{
Daniel Moura Nogueira* \\ José Luiz Ragazzi**
}

RESUMO: O presente artigo parte da análise do comando constitucional da razoável duração do processo em confronto com a realidade fática e a práxis jurídica na aplicação das normas do processo civil, tendo em vista a realização daquele comando, especificamente de pretensão em que há parcela incontroversa, sob pena de norma constitucional e infraconstitucional apenas simbólica.

PALAVRAS-CHAVE: Norma constitucional. Processo civil. Duração processual. Pedido incontroverso.

ABSTRACT: This article discusses the constitutional provision about reasonable length of proceedings and its confrontation with reality and judicial practice regarding the application of civil procedure law having in mind the application of that command, especially in claims where there is uncontroversial suitor taking the risk that the constitutional provision above and statutes related to it are just symbolic.

KEYWORDS: Constitutional provision. Civil procedure law. Reasonable length of proceedings. Uncontroversial suitor.

* Especialista em Direito Processual Civil; Direito Civil-Difusos e Coletivos pela Escola Superior do Ministério Público de MT e RS. Mestrando em Direito pela Instituição Toledo de Ensino-ITE, Baurú-SP. Professor de Direito Processual Civil na UNIC-Universidade de Cuiabá, Campus Sinop. Advogado em Sinop-MT. E-mail: advdanos@ vsp.com.br

**Mestre pela ITE-Bauru, Doutor em Direito Processual Civil pela PUC-SP, Professor do Mestrado e Doutorado da ITE- Bauru e de vários cursos de pós-graduação do País. 


\section{INTRODUÇÃO}

Por que o tema da duração razoável da tutela Estatal tornou-se alvo de inúmeras doutrinas, comentários, artigos etc.? É cediço que o tema é instigante, pois, tudo o que se espera, o que se aguarda, chegando antes do momento comum, traz ao receptor clima de satisfação, alívio prazeroso e imediato em seu espírito.

O ser humano é dotado disso. Esperar, aguardar não é elemento próprio da natureza humana, pelo menos no âmbito do desejo e da satisfação. Não faz parte da natureza humana como algo conscientemente natural, pacífico.

Ninguém - sem exceção (nem mesmo dos incapazes) - aceita esse elemento ínsito no sistema humano com tranquilidade, paz interna normal. Se aguarda o faz contrário à natureza interna do ser; nosso espírito não se sente feliz quando não consegue imediatamente o que quer.

Com certeza, a psiquiatria e a psicologia enfocam isso de maneira distinta, como algo necessário de tratamento a alcançar cura; o intelecto deve ser condicionado ao elemento natural - esperar.

Ora, mas nem mesmo a doutrina que estuda o intelecto do ser consegue aguardar tanto tempo a fim de que o paciente possa ser restaurado com suas análises. Logo, volta ao status quo, o ser como ser não harmoniza com o fator espera.

E, no tema de busca da tutela jurisdicional, muito menos se espera; ou melhor, esse choque espiritual do ser contra o aguardar fica potencializado, tendo em vista os aguçares dos ânimos pela interpretação de que seu direito líquido e certo fora ferido ou não satisfeito pela parte contrária.

O credor, o demandante, tem em seu âmago que a justiça seja feita já, agora!

Cumpre esclarecer diante disso que, se se trata de tutela de interesses, essa existe em razão do conflito desses (interesses), levando-se em conta ser o interesse uma "situacón favorable a la satisfacción de una necesidad", e as necessidades são ilimitadas diante da limitação dos bens. ${ }^{1}$

Assim, como ensinava Carnelutti, "surge conflicto entre dos intereses cuando la situación favorable a la satisfacción de una necessidad excluye la situación favorable a la satisfacción de una necesidad distinta". ${ }^{2}$

Solução? Ao Estado cumpre tomar as medidas possíveis e impossíveis a fim de cumprir seu papel de intermediador do ser humano para o desígnio precípuo da jurisdição: a pacificação social.

1 Francesco Carnelutti, "Sistema de Derecho Procesal Civil”, v.1. Uteha Argentina, Buenos Aires, 1944, p.16.

2 Idem, ibidem. 
Dessa vertente é que a Constituição Federal consagrou o princípio da razoável duração do processo, prevendo, em seu art. $5^{\circ}$, incisos XXXV e LXXVIII, respetivamente, “a lei não excluirá da apreciação do Poder Judiciário lesão ou ameaça a direito"; e que "a todos, no âmbito judicial e administrativo, são assegurados a razoável duração do processo e os meios que garantam a celeridade de sua tramitação".

Logo, a norma magna determina a todos um processo célere numa efetividade eficaz, cumprindo visualizar se na práxis forense e na dogmática jurídico-processual a letra da Carta Magna possui concretude diante dos casos concretos, ou se tão somente trata de uma norma simbólica, no sentido de imponência dos comandos, prevendo resposta jurisdicional em tempo satisfatório, mas, na prática não existe.

\section{GÊNESE UNIVERSAL DA EXISTÊNCIA DO PROCESSO}

Ora, todo esse universo de situações existe em face do antagonismo nas posições a que se colocam as partes e é aí que reside a controvérsia acerca de determinado pleito, ou seja, há uma incógnita sobre onde reside a verdade.

Carnelutti já afirmava que, quando duvidosa a razão do pedido ou da contestação, nasce uma questão e, quando a lide apresenta uma ou mais questões, tem-se a controvérsia, motivo de análise e solução pelo Estado através da decisão. ${ }^{3}$

Pode-se concluir com todo esse circunlóquio que a controvérsia, como centro de um conflito, existe desde o surgimento de mais de uma pessoa na criação do universo, e será assim até o fim.

Seguindo essa linha de raciocínio, Werner Goldschmidt apresenta quatro obstáculos para realização da justiça, sendo que o primeiro contém a "discrepância entre el carácter infinito del mundo y el carácter finito de la justicia”. Assim preleciona o autor:

\footnotetext{
Dentro de una situación jurídica pendiente, los acontecimientos sobrevinientes pueden ejercer cierta influencia sobre derechos y obligaciones de los interesados. Lo por venir altera el sentido del pasado. La mora de un deudor o la imposibilidad del cumplimiento de una prestación, por ejemplo, producen repercusiones sobre los derechos de las partes. Vimos antes que el juicio definitivo sobre la justicia en una situación cualquiera no se debiera dictar sino el día del Juicio Final. Como ello evidentemente resulta irrealizable, las personas, autorizadas a repartir bienes y males, declaran las situaciones, en determinadas circunstancias, conclusas. No obstante, la exigencia radical de justicia de que en un principio todas las situaciones debieran considerar se hasta el final como pendientes, se impone a veces aun con respecto a dichas situaciones conclusas y engendra reformas jurídicas de las mismas. De lo que antecede se desprende fácilmente que todo el distingo entre situaciones pendientes y conclusas es forzosamente precario y que las situaciones jurídicas llamadas conclusas poseen siempre un carácter inestable. ${ }^{4}$
}

3 Francesco Carnelutti, "Instituições do Processo Civil", Classic Book, v. 1, n. 13, p. 86.

${ }^{4}$ La ciencia de la justicia (Dikelogia), Editora Aguilar, Madrid, 1958, pp. 59/60. 
Duas razões há para o dispêndio de tempo necessário na solução dos conflitos, ou seja, o surgimento da controvérsia sobre um interesse disputado por dois polos; e, em segundo, a busca aprofundada por parte do Estado-julgador sobre a verdade das afirmações.

Isso somado ao monopólio Estatal da função supridora dos interesses particulares em conflito, impõe a criação de mecanismos técnicos a fim de consumar esse desiderato. Tem-se, então, o instrumento denominado processo, como algo supremo de realizar a consecução prática da justiça em condição participativa dos litigantes.

\section{SISTEMA PROCESSUAL}

Por outro ângulo de visão de sistema, como o Estado organizado avocou a direção da solução dos conflitos entre os indivíduos da sociedade, tem-se por imprescindível a presença de um terceiro ente - o próprio Estado na pessoa do julgador - como responsável em dizer qual polo antagônico está a merecer a pretensão ou a outorga do direito invocado ou resistido.

Tal ofício torna-se impossível sem o conhecimento percuciente do conflito - da divergência entre os dois polos. Circunstância que levou, obrigatoriamente, o ente Estatal a organizar sua tarefa para não pender nem para um, nem para outro lado dos dois pontos conflitantes, o que o levou, também, a determinar atitudes no sentido de averiguar; investigar a verdade das afirmações das partes em conflito, pois, entende-se que o que se prova é a existência da verdade sobre o fato alegado. ${ }^{5}$

Ante tal circunstância, devem-se seguir caminhos, como as imprescindíveis técnicas da instrução processual pra se chegar a uma solução lógica, justa e real, com o fim último de pacificar a relação conflitante, como finalidade primordial da natureza da jurisdição.

Justamente esses caminhos imperiosos é que provocam o fator demora na entrega da solução de um conflito, uma vez que o terceiro ente não tem a capacidade onisciente e onipresente para conhecer o que é justo em face do litígio até então apresentado.

Não se pode, por outro lado, olvidar de que o tempo gasto com a solução do conflito é consequência exigida pela própria natureza da existência dos dois polos conflitantes.

Em contrapartida, muito se fala acerca de que o Estado, vedando a tutela privada, obrigou-se a solucionar os conflitos de forma a promover satisfação como se o conflito não tivesse nascido.

Porém, qualquer descontentamento em face da resposta do Estado não deve ir ao extremo, pois indaga-se: seria preferível a justiça privada à pública? Muito se reclama, porém ninguém pretende a volta às origens da actio per manus injectionem.

${ }^{5}$ Cfr. Nogueira, Daniel Moura. A prova sob o ponto de vista filosófico. In: Prescrição, decadência e prova. Gilmar Ferreira Mendes, Rui Stoco (Org.). Coleção doutrinas essenciais: direito civil, parte geral, v. 5. São Paulo, Ed. RT, 2011, p. 899. 
Tal assertiva jamais poderá ser escusa para o ente Estatal esquivar-se de suas obrigações ou realizá-las de forma desidiosa. O cidadão encontra-se na esfera da maior e melhor proteção Estatal, em qualquer área da necessidade humana.

\subsection{TEMPO E PROCESSO}

Desde tempos a doutrina tem se preocupado em pesquisar, criando teses, no concernente ao prazo - período de tempo -, que leva o processo para sua conclusão e efetiva entrega da tutela jurisdicional.

Não olvidando, também, que a própria parte é um tanto quanto responsável por possível demora na entrega da prestação jurisdicional, com a utilização de recursos e manejos o quanto puder.

Quanto a esse comportamento da parte, o Min. Cesar Asfor Rocha chegou ao extremo de assegurar que "o contraditório e a recorribilidade no processo de conhecimento tendem ao infinito". ${ }^{6}$

E, a isso não se pode impor um maior peso, tendo em vista que, se a própria lei permite, passa a ser um direito fundamental a utilização dos recursos colocados à disposição.

Em sede de direito material privado e sua consecução real por meio do processo civil, faz-se uníssono o clamor por rapidez na tramitação e na conclusão do processo diante de uma demanda, quer judicial, quer administrativa.

Reclamos, estudos e manifestações da doutrina levam o Estado a uma reforma em seus aparatos judiciais, a fim de tentar conferir a tutela jurisdicional com maior celeridade, vindo a criar, como supra, dentre outros, o comando do inciso LXXVIII, do art. $5^{\circ}$ da Carta Magna, que estabelece como direito fundamental a rápida solução do litígio, acrescido com a emenda 45/2004.

Em se tratando de norma constitucional de justiça e seu real conceito, José Luiz Ragazzi questiona "mas à que justiça? Seria aquela que, ao final de cinco ou dez anos, emite uma sentença de mérito determinando quem tem direito ao bem da vida, independentemente dos danos causados pela demora do processo e do sofrimento do jurisdicionado?".7

Por essas e outras razões, não eram sem tempo medidas de aceleração, pois há tempo o Brasil aderiu ao Pacto São José da Costa Rica, e dentre outras normativas o art. $8^{\circ}$, parágrafo 1 , prevê tal celeridades, como prescreve:

\footnotetext{
${ }^{6}$ A luta pela efetividade da jurisdição, São Paulo: RT, 2007, p. 82.

7 Tutela antecipada nas relações de consumo. São Paulo, Editora Juarez de Oliveira, 2002, p. 4.
} 
Art. $8^{\circ}, 1$ : Toda pessoa tem direito a ser ouvida com as devidas garantias e dentro de um prazo razoável, por um juiz ou tribunal competente, independente e imparcial, estabelecido anteriormente por lei, na apuração de qualquer acusação penal formulada contra ela, ou para que se determinem seus direitos ou obrigações de natureza civil, trabalhista, fiscal ou de qualquer outra natureza.

A celeridade tem rendido explanações doutrinárias, fartando-se a doutrina do assunto para escrever sobre tempo no processo, como cobrança, ao Estado, por um prazo razoável na solução de demandas a si apresentadas, no cumprimento de seu papel jurisdicional e em nome de um direito fundamental do cidadão.

Por sua vez, o Conselho Nacional de Justiça impôs normas administrativas justamente para tentar erradicar a demora na prestação jurisdicional, com a solução das demandas até então se arrastando nos gabinetes e cartórios judiciais. Cria, dessa forma, metas no sentido da celeridade processual.

Por outro ângulo, alguns fatores como explosão demográfica; tarefas excessivas e desenfreadas do homem; aumento de casos enfim, levaram o jurisdicionado a sentir certa angústia quando se trata de esperar - aguardar por algo.

\subsubsection{Noção de Prazo (Tempo) Razoável no Processo}

As alegações de demora e de que o processo tenha duração razoável, tout court, não são suficientes. Necessário se faz atentar para o fator de que também são exigidas do Estado outras garantias constitucionais, como o contraditório, a ampla defesa etc.

Se o número de demandas é crescente dia a dia; se o judiciário tem o papel de garantir ao cidadão administrado, que porta o direito material a seu favor, precisamente ${ }^{8}$ o que tenha direito a obter: como conciliar tudo isso em um curto espaço de tempo?

Não se apregoa aqui que o modelo atual seja razoável. Todavia, não se pode olvidar de que o processo - literalmente falando de atos processuais - tem sua marcha préestabelecida por atos, prazos, participações dos envolvidos e, isso, enseja (humanamente) espaço de tempo, cronologicamente falando, para sua consecução real.

O juiz não pode prescindir de toda essa gama de fases para sentenciar uma demanda a seu bel prazer, simplesmente para envaidecer-se de tê-la cumprido em curtíssimo espaço de tempo, sob pena de ferir outros comandos, não menos importante que a duração razoável, como, v.g. a fundamentação das decisões (CF. art. 93-IX); análise do complexo probatório; audiência preliminar do art. 331, do CPC, entre outros.

Até porque se trata de processo de cognição, rito comum, em que o complexo do litígio, por vezes, impõe uma busca percuciente, a fim de não fazer injustiça com a

8 Cfr. Proto Pisani, Andrea. Appunti sulla tutela di condena, in Studi in onore di Enrico Tullio Liebam, v. 3, Milano, editora Giuffrè, 1979, p. 1.738-9. 
parte que tem razão, levando ainda a uma demora maior com a interposição de recursos. Se bem que, caso a parte que tenha razão venha a perder a demanda, também poderá intentar os remédios recursais.

A doutrina busca, ao tentar convencer os operadores do sistema judiciário, é que não se aplaine a máquina em apenas um nível, ou seja, aplicando um único provimento para todas as situações concretas. Mas, sim, regular a aplicação do direito ao caso concreto, segundo ocorrer no plano fático em nível de algo controvertido ou incontroverso, aplicando, conforme o evento, o procedimento que mais se enquadrar; mesmo que prescindindo algumas formalidades tidas por dogmas.

A propósito, Frederico Augusto Leopoldino Koehler traz a advertência de DiezPicazo Gimézes, para quem: “afirmar que o caráter razoável ou não de um atraso depende, entre outras coisas, da duração média dos processos do mesmo tipo, equivale a advogar que as deficiências estruturais da administração da justiça também justificam tais dilações". ${ }^{9}$

Impõe, por conseguinte, um exercício de razão por parte dos operadores do direito, máxime os magistrados que estão com a tarefa de julgar, para discernir hipóteses de incontrovérsia e relegar as fórmulas meramente inócuas como v.g. audiência de instrução para situações em que parte do pleito encontrar-se confessado ou não contestado, ou incontroverso.

No sistema italiano, Ferruccio Tammaseo assevera acerca do critério para duração do processo:

Il criterio dela ragionevole durata divente ora, per affetto dell'art. 111, cpc., Cost., criterio per stabilire la conformità d'un determinato modello processuale con i principi costituzionali del giusto processo: una valutazione, in concreto, molto difficile per il motivo che la durata del processo piuttosto che dai difetti della legislazione dipende soprattutto dalle carenze dell'apparato giudiziario e dei servizi dell'amministrazione della giustizia, oltre che da radicati atteggiamenti del costume forense. ${ }^{10}$

Assim como o tempo de duração e a realização dos atos processuais, a fim de uma sentença justa, devem-se levar em consideração as circunstâncias do caso concreto, não colocando todas as situações em um mesmo pacote de soluções, para obter o mesmo tratamento. Isso é retrógado e ineficaz ante a elevada cultura jurídica atual e a necessidade de despir dos velhos chavões.

9 A razoável duração do processo, Editora Jus Podivm, Salvador, 2009, p. 95.

${ }^{10}$ Lezioni di diritto processuale civile. v. I, Padova: Cedam, 2002, p18. Tradução livre: O critério da razoável duração torna agora, por força do art. 111 da constituição, critério para estabilizar a conformidade de um determinado modelo processual com os princípios constitucionais do justo processo: uma valoração concreta muito difícil pelo motivo que a duração do processo mais precisamente que os defeitos da legislação depende, sobretudo da carência do aparato judiciário e dos serviços da administração da justiça, além da radical postura dos costumes forenses. 
Nessa mesma trilha, assegura Cruz e Tucci que, para a resposta ser "a mais plena possível, a decisão final deve ser pronunciada em um lapso de tempo compatível com a natureza do objeto litigioso". ${ }^{11}$

Por isso, a noção de tempo no processo não deve ser levada à livre criação de cada um diante da ideia de defender interesses individuais, isolando o interesse geral da coletividade.

Mas, deve-se conjecturar situações em que a controvérsia haja superada diante de uma verossimilhança, ou diante mesmo da incontrovérsia; com o perigo de demora; e, ainda, com a aplicação da cognição que adequar com a realidade, diante dos primeiros itens.

Ou seja, diante de incontrovérsia de um ou mais dos pedidos cumulados, deve-se aplicar cognição cabal que esgote o percurso da função jurisdicional com a entrega do bem da vida a quem de direito, sem maiores delongas com definitividade, levando sempre em consideração que uma prestação jurisdicional somente ocorre em tempo razoável se ela ainda for útil ao jurisdicionado.

\section{A NORMA CONSTITUCIONAL DA RAZOÁVEL DURAÇÃo DO PROCESSO}

\subsection{CONCRETUdE PRÁtICA DO DIREITO OU NORMA SIMBÓLICA - LEGISLAÇÃO-ÁLIBI?}

É cediço do texto constitucional de que ao Estado impõe solução rápida aos processos a si confiados.

Por outro lado, cumpre à dogmática jurídica e ao próprio julgador a distinção sobre a relação entre simples texto e norma constitucional ou realidade constitucional ${ }^{12}$, não ensejando apenas simbolicamente.

Ao se falar de constituição simbólica, tem-se a concepção de "texto carente de concretização normativo-jurídica" ${ }^{13}$

Marcelo Neves afirma que a relação entre texto e realidade constitucional não se trata da clássica dicotomia entre conteúdo e realidade, "mas sim, do problema referente à 'concretização' das normas constitucionais, que, nessa perspectiva, não se confunde com o texto constitucional". ${ }^{14}$

${ }^{11}$ José Rogério Cruz e Tucci. Duração Razoável do Processo. In: JAIME, Fernando Gonzaga; FARIA et all., (Coords.). Processo Civil - Novas Tendências: Homenagem ao professor Humberto Theodoro Junior. Belo Horizonte, Editora Del Rey: 2008. p. 435.

${ }^{12}$ Cfr. Marcelo Neves. Constitucionalização Simbólica. 3. ed. São Paulo: Martins Fontes, 2011, p. 90.

${ }^{13}$ Marcelo Neves. Constitucionalização Simbólica, cit. p. 1.

${ }^{14}$ Constitucionalização Simbólica, cit. p. 83. 
Todavia, ainda que haja texto que possa complementar a norma; ainda que a lei ordinária tente dar concretude ao comando Constitucional, se a realidade prática não conferir o real direito líquido ao jurisdicionado, como no presente tema, por lógica, a norma da carta magna é carente de efetividade eficaz. Ou seja, o "sentido negativo da constitucionalização simbólica", como pontifica Marcelo Neves. ${ }^{15}$

O Judiciário (o Estado-juiz) não tem construído normas ${ }^{16}$ no sentido do direito como ciência, adequando-as ao caso concreto, uma vez que os juízes realizam a jurisprudência (jurisprudência), decisões em série, não fazem juris-ciência.

Impõe-se assim, descobrir a norma escrita no texto, a verdadeira aplicação da hermenêutica, diferenciando este instituto da simples interpretação.

Luiz Alberto David Araujo e Vidal Serrano Nunes Júnior asseveram acerca de tal diferença. Para estes autores, “a expressão 'interpretar' carrega a ideia de esclarecimento, de compreensão de conteúdo, de extrair de uma norma o seu sentido e o seu alcance". Já a hermenêutica é apresentada como sendo "o ramo do conhecimento científico que estuda a interpretação". ${ }^{17}$

Eduardo J. Couture já dizia, acerca da constituição e seus textos regulamentares, que o caráter elementar dessas ideias não confere significação científica, porque elas constituem, na verdade, somente um ponto de partida para investigação posterior. ${ }^{18}$ Disso decorre que a lei tão somente nos entrega uma referência normativa para uma construção, já que o direito é um fenômeno histórico e cultural.

E, em se falando do fenômeno cultural, não há que se olvidar que a cultura é aquilo constantemente transformado pelo ser, diferentemente da ciência exata em que o falso e o verdadeiro se impõem, como na matemática. O direito não é o mundo da matemática, pois depende do razoável, do proporcional.

Para o direito não há falso e verdadeiro ${ }^{19}$, por conseguinte, não se adequa à ciência exata, uma vez que a sociedade não é mera somatória de pessoas, mas trata-se de elementos em relacionamento.

E esse complexo todo de comentários há em nome dos valores constitucionais, já que a Constituição reproduz valores [tudo na Constituição são valores], e, em assim

${ }^{15}$ Idem, ibidem, p. 91.

16 Quando aqui se refere à "não uma construção" não se quer dizer no sentido de elaborar leis, mas que os julgadores não constroem leis, no sentido de dar força à norma à partir da interpretação ao caso concreto.

${ }_{17}$ Curso de Direito Constitucional, 14. ed. São Paulo: Saraiva, 2010, p. 91.

${ }^{18}$ Estudios de derecho processal civil - La constitución y el processo civil. Tomo I, Ediar, Soc. Anón Editores. Buenos Aires: 1948 p.19. Texto no original: "El carácter elemental de estas ideas no les quita significación científica, porque ellas constituyen, em verdade, sólo un punto de partida para la investigación ulterior".

19 Fala aqui na inexistência de falso e verdadeiro no sentido da exatidão daquilo que é justo, não se aplica, por óbvio no plano probatório. 
sendo, devem impactar a sociedade com a satisfação daquilo que impõe ao Estado a resolução, pena de ser apenas simbólica.

No direito europeu, Tomaseo afirma que, em países como a Itália, o tema é tratado como um direito sistémico, no qual a duração média do processo ficou algo anormal, a ponto de a Corte Europeia dos direitos do homem, muitas vezes ter condenado o Estado italiano a dar igual satisfação às partes prejudicadas pela doentia duração dos processos. ${ }^{20}$

No sentido de equilibrar a utilidade do tempo não vulnerando a efetividade, o mestre italiano assevera:

La durata del processo dev'essere 'ragionevole' tale cioè da consentire alle parti l'esercizio del diritto di defesa che richiede ovviamente del tempo per essere esercitado in modo utile. Per contro, un'eccessiva durata del processo ne vulnera gravemente l'efficienza e con ciò stesso vulnera il principio d'effettività della tutela giurisdizionale implicitamente presupposto dall'art. 24, pr., Cost.; inoltre, entra inconflito con il principio di legalegalità, poiché la durata abnorme del processo consente il protrarsi nel tempo di situazioni antigiuridiche, provocando allarme sociale oltre che il giustificato risentimento della parte che ha ragione. ${ }^{21}$

O equilíbrio é algo imprescindível a toda natureza humana, porém tal elemento não é, nem poderá ser álibi para justificar a vulnerabilidade do processo diante de quem tem razão e, máxime, no presente caso da incontrovérsia parcial da demanda.

Impõe, por conseguinte, o alarde da sociedade contra a inconstitucionalidade da norma simbólica, a fim de levar à sua concretude prática.

\subsection{LEGISLAÇÃO-ÁLIBI}

Se a sociedade exige do Estado uma resposta, uma solução para os conflitos através da lei, isso provoca a atuação obrigatória do ente estatal.

Com objetivo de mitigar a turbação provocada pela manifestação social cria-se, então, a norma contendo algo almejado pelos jurisdicionados.

Com a presença e a vigência da norma, os ânimos populares se esfriam, provocando, no senso espiritual do ser, um alívio, tendo em vista a presença de um comando.

Com esse comportamento, o Estado consegue "descarregar-se de pressões políticas ou" apresentar-se "como sensível às exigências e expectativas dos cidadãos". ${ }^{22}$

Como exposto acima, mesmo havendo norma regulamentadora do comando Constitucional se, do ponto de vista instrumental, não houver efetividade concreta, tem-se apenas um signo à norma maior.

\footnotetext{
${ }^{20}$ Ferruccio Tommaseo, Lezioni cit, p.17.

21 Idem, p. 17.

${ }^{22}$ Marcelo Neves, op. cit. p.37.
} 
Por outro viés, se a norma traz comando efetivo e eficaz, mas na concretude o Estado não consegue o mínimo de efetivação, tem-se que esta norma ordinária é tão somente, como pontifica a doutrina alemã, uma legislação-álibi. ${ }^{23}$

Já ensinava Kindermann, citado por Celso Neves, que:

Objetivo da legislação simbólica pode ser também fortificar 'a confiança dos cidadãos no respectivo governo ou, de um modo geral, no Estado’. Nesse caso, não se trata de confirmar valores de determinados grupos, mas sim de produzir confiança nos sistemas político e jurídico.

A essa formulação do problema subjaz uma crença instrumentalista nos efeitos das leis, conforme a qual se atribui à legislação a função de solucionar os problemas da sociedade.

Parece, portanto, mais adequado afirmar que a legislação-álibi destina-se a criar a imagem de um Estado que responde normativamente aos problemas reais da sociedade.

Nesse sentido, pode-se afirmar que a legislação-álibi constitui uma forma de manipulação ou de ilusão que imuniza o sistema político contra outras alternativas, desempenhando uma função 'ideológica'. ${ }^{24}$

Se o Estado cria uma lei que, aparentemente, vai ao encontro da necessidade do cidadão, mas, avocando como exemplo o caso em estudo, no qual parte da pretensão do autor encontrar-se incontroversa [sem resistência do réu], porém sob o ponto de vista instrumental, em nada é concretizado, pois [atualmente o juiz] outorga ao autor o bem da vida, pelo qual não houve resistência $\left[\S 6^{\circ}\right.$, art. 273, CPC], apenas de forma provisória, nesse caso a norma tão somente serviu (ou serve) para "dar a aparência de uma solução dos respectivos problemas sociais ou, no mínimo, da pretensão de convencer o público das boas intenções do legislador". ${ }^{25}$

De tudo, conclui-se que não há qualquer sentido a previsão constitucional à efetividade célere de um direito e uma resposta do Estado a quem reclama por um direito violado de forma a voltar ao status quo (art. $5^{\circ}$, XXXV e LXXVIII, CF) se no momento de conferir o bem da vida, o sistema que in casu é inconstitucional, esbarra, trava em dogmas, o que ocorre na prática em litígios com parcela do pedido incontroversa. Essa particularidade tem sido conferida de forma deficiente, em que a decisão interlocutória não consegue consumar definitivamente o direito ao autor, como se viu.

Se dentro do mesmo sistema uma determinação choca-se com outra, levando a uma antinomia jurídica, impedindo o cumprimento - impedindo a efetividade de previsão constitucional -, não há que se perdurar essa situação injusta, devendo de plano o julgador aplicar a norma maior, fazendo justiça social, dirigindo o processo conforme o bom senso, tomando atitudes drásticas, mesmo que em tese possa contrariar o sistema,

${ }^{23}$ Tese proposta por Harald Kindermann, In: Marcelo Neves. Constitucionalização Simbólica. 3. ed. São Paulo: Martins Fontes, 2011, pp. 36/41.

${ }^{24}$ In: Marcelo Neves. Constitucionalização Simbólica, cit. pp. 36 a 40.

${ }^{25}$ Marcelo Neves cit. p. 39. 
tudo em nome da necessidade de quem pleiteia e em face do princípio constitucional da congruência.

José Roberto S. Bedaque reforça essa ideia de uma tutela real, independentemente de dogmas processuais, quando afirma de forma brilhante que "o que importa é o escopo previsto na lei, não o meio pelo qual se tenta alcançá-lo". ${ }^{26}$

Não se deve levar muito em consideração letras da lei determinando siga tal e qual caminho, quando se tem em vista um direito líquido, certo e exigível de um cidadão necessitado da tutela Estatal, cujos comandos emanados da lei maior seja no sentido da real prestação sem delongas triviais.

Dessa superação do formalismo jurídico e processual, pugna Eduardo Cambi, na aplicação do pós-modernismo do direito irresignado à não efetivação do direto em nome de técnicas formalísticas, em que enseja valoração do "conteúdo em detrimento do apego excessivo à forma". ${ }^{27}$

Com muita propriedade, citando Eduardo Carlos B. Bittar, Cambi ${ }^{28}$ pontifica que o culto excessivo ao método reduz o acesso à justiça apenas aos "que sobrevivem as armadilhas e artimanhas criadas pelo sistema jurídico", e traz (dentre muitos existentes) um exemplo nítido de ausência de justiça em prol do formalismo processual, como a preclusão consumativa, especificamente ao preparo do recurso de apelação no processo civil, em que, no mesmo instante do protocolo, já enseja anexar a guia recolhida, caso contrário, mesmo dentro do prazo não mais poderá fazê-lo, o recurso estará deserto (art. 511, do CPC). ${ }^{29}$

\section{RAZOÁVEL DURAÇÃo do PROCESSO COM A IMEDIATA CONCESSÃo DA TUTELA PELA INCONTROVÉRSIA DO PEDIDO - TENTATIVA DE ATIVAR A NORMA SIMBÓLICA}

Não obstante o tema encontrar-se sob análise no projeto do novo $\mathrm{CPC}$, tratado com o mote de tutela de evidência, como se vê do art. 278, inciso II, do projeto de lei n. ${ }^{\circ}$ 8.046/2010, cuja previsão será uma solução definitiva à lide, o certo é que até que entre em vigor o novo preceito, impõe estudos sobre o que se tem de novas viabilidades de diminuição do tempo do processo.

26 "Efetividade do processo e técnica processual", Malheiros, 2006, p.413.

${ }^{27}$ Neoconstitucionalismo e Neoprocessualismo - direitos fundamentais, políticas públicas e protagonismo judiciário. 2. ed. rev. e atualizada. São Paulo: Editora Revista dos Tribunais, 2011, p.115.

${ }^{28}$ Idem, p. 116.

29 A isso se dá também o princípio da eventualidade ou da concentração dos atos processuais, tendo em vista que o processo é um instrumento e, como tal, deve ter resultados práticos. 
O que se pretende, portanto, é a demonstração de que a norma Constitucional houve por determinar a celeridade efetivamente eficaz da tutela Estatal.

Mais adiante, também, que a norma infraconstitucional houve por regulamentar especificamente nas medidas de urgência do processo civil.

E, um pouco mais restrito, no comando do parágrafo $6^{\circ}$ do art. 273 , do $\mathrm{CPC}$, para as hipóteses concretas de pretensões parcialmente incontroversas, seja de imediato conferido o bem da vida ao credor de forma definitiva.

Todavia, a concretização desse comando é travada pelos dogmas e padrões de uma epistemologia ortodoxa no dia a dia forense, fazendo com que uma pretensão incontroversa em litígios entre particulares, não seja definitivamente outorgada a quem de direito, a despeito de obedecer às normas procedimentais e formais do sistema, como se verá.

Tem-se um confronto entre comandos e normas, ou ainda interpretação e aplicação dessas normas em que, no mesmo sentido, preleciona Celso Neves, embasado em Kindermann, para quem "é evidente que as leis não são instrumentos capazes de modificar a realidade de forma direta, pois as variáveis normativo-jurídicas defrontam-se com outras variáveis orientadas por outros códigos e critérios sistêmicos". ${ }^{30}$

Harald Kindermann denomina esta situação como legislação-álibi, pois, a despeito da existência da normatização, como aparente resposta do Estado, a sociedade, na realidade, não encontra alicerce legal para solução do litígio de forma como consta das letras da Lei. Ou seja, ainda que haja texto não há concretude. ${ }^{31}$

Acrescem a essa ideia as ponderações de Tommaseo, para o exercício de poder do juiz na cultura jurídica italiana, com interpretação dos parâmetros legais da tutela de urgência, para uma correta aplicação da lei, em que preleciona:

A vasta dimensão dos poderes, que a letra da norma contida nos arts. 700 e seguintes, do CPC italiano, parecer reservar ao juiz, não exonera o interprete da busca dos parâmetros entre os quais e tais poderes devem ser exercitados; busca que deve ser realizada levando em conta - para repetir as mesmas palavras da Corte constitucional - todos os limites que podem ser deduzidos de uma correta interpretação da disciplina da tutela urgente no âmbito do sistema vigente. ${ }^{32}$

\footnotetext{
${ }^{30}$ A Constitucionalização Simbólica cit. p. 39.

31 Celso Neves, op. cit. 39.

${ }^{32}$ Ferrucio Tommaseo, I Provvedimenti D'urgenza - Struttura e limniti della tutela anticipatoria. Padova:
} Cedam, 1983, p. 209. Em tradução livre. Consta do original: "La vasta latitudine dei poteri cha la lettera dela norma contenute negli artt. 700 ss. c.p.c. sembra riservare al giudice, non esonera l'interprete dalla ricerca dei parametri entro i quali tali poteri debbono essere esercitati, ricerca che deve essere compiuta tenendo conto - per ripetere le porole della stessa Corte costituzionale - di tutti i limiti desumibili da una correta interpretazione della disciplina della tutela urgente nell'àmbito del sistema vigente". 
E, no presente tema, não estamos falando de medida acautelatória do processo cautelar em que tão somente ampara o bem em discussão, a fim de evitar perecimento, mas, sim, de uma parcela de um pedido admitido como incontroverso.

Não se olvida que o legislador buscou criar possibilidades, caminhos para mitigar a situação do tema tempo - espera na entrega da tutela jurisdicional.

Dentre muitas, destaca-se na tutela jurisdicional privada - dissídios entre particulares, nas hipóteses de demandas comportando as relações sociais entre indivíduos de per si -, situações em que (i) havendo aparência da verdade do alegado; (ii) algo que ao mundo jurídico se encontrar inquestionável; (iii) que a parte inocente não corra risco de dano irreparável; seja de imediato entregue ao cidadão, como se vê na dicção do par. $6^{\circ}$ art. 273, CPC.

Portanto, no presente ensaio, a questão que se enfrenta é justamente a de que, diante de um conflito de interesses, a parte a quem é reclamado certo comportamento e, por ação ou omissão sua, deixa de resistir a certa(s) parcela(s) do pleito, tornando isenta do conflito, logo, por óbvio, sem conflito - incontroverso.

Diante dessa circunstância é que deve atuar a resposta Estatal de forma eficaz, outorgando, a quem de direito, aquilo que se pretender de imediato, quando ausente a controvérsia.

Para tal situação, o ordenamento jurídico-processual constante do par. $6^{\circ}$, do artigo 273 do CPC, tem-se um comando que vai ao encontro do fator tempo dentro da marcha processual, reduzindo-o ante a verificação de incontrovérsia quanto a pedidos, partes deste, ou no caso de cumulação.

Assim pode-se referir que o atual sistema prevê, além da antecipação da tutela, de forma genérica com base na verossimilhança e no perigo da demora, a antecipação com base na incontrovérsia, prevista para parcela de um pedido ou nos casos de pedidos cumulados um ou uns deles houver por incontroverso.

Porém, ante essa propalada aceleração no deslinde de questões judiciais (pois de imediato o Juiz deverá outorgar o pleito deduzido, o que seria apenas uma vasta e longa averiguação), tem-se que esse comando, quando de sua vigência, já se chocava com a natureza de outros institutos processuais.

Não se nega o benefício, mas não há, também, que se olvidar que se esbarra no sistema que há muito vem norteando a distribuição da justiça.

O propósito é que uma vez incontroverso, de imediato já resolva a demanda, nesta parte, não apenas antecipar a tutela como propõe o caput do art. 273, do CPC. Apenas antecipar sem seus resultados práticos é o trabalhar em vão.

Assim, para que o comando Constitucional não seja apenas simbólico e, consequentemente, uma legislação infraconstitucional álibi, neste particular, impõe que 
dentro do mesmo processo o juiz confira sentença de mérito definitiva a fim de execução imediata $^{33}$ da parte incontroversa.

Eduardo Cambi, quando ministra acerca do neoconstitucionalismo e neoprocessualismo, pontifica com muita maestria no mesmo sentido em que:

Propõe que, para os direitos serem garantidos e satisfeitos concretamente, é necessário formular técnicas idôneas para garantir o máximo grau de efetividade dos direitos fundamentais. Isso implica concluir que, no plano da jurisdição constitucional, os juízes não estão apenas sujeitos às leis, mas também a análise crítica de seu significado, como meio de controle da legitimidade constitucional. ${ }^{34}$

Não se olvida que essa tese provoca questionamentos contundentes, como já vem acontecendo na doutrina, como v.g., se houver recurso contra a sentença? Como ficariam os autos do processo, sendo que da parte sentenciada deva subir ao tribunal? Por que não manejar a decisão interlocutória dessa parte incontroversa sujeitando a recurso de agravo de instrumento?

Não se nega que o tema é complexo e enseja uma gama de tempo e espaço para discorrer acerca da aplicabilidade justa, quando se trata de algo incontroverso em um litígio.

Não obstante, as questões não ficam sem respostas, justamente em nome da congruência constitucional, a fim de suas normas não se tornarem meramente simbólicas.

A práxis e a dogmática jurídica não devem manter as críticas ortodoxas acerca do sistema. Impõe criticar algo novo, uma epistemologia moderna das significações, como bem ponderou o professor Luís Alberto Warat, quando propõe a substituição da hegemonia dos textos jurídicos "pelo princípio da heteronímia significativa". ${ }^{35}$

Assim, ainda que a jurisdição seja una, tal unicidade não se deve aplicar ao processo e a seus corolários, diante de casos de incontrovérsia parcial de uma pretensão, como na visão clássica proposta por chiovendiana della unità e unicità della decizione. ${ }^{36}$

Em nome do valor constitucional e da norma ordinária efetivamente eficaz impõe, diante da parcela incontroversa do litígio, que seja cindido o processo e o julgamento

${ }^{33}$ Execução imediata, respeitando os recursos cabíveis e seus efeitos.

${ }^{34}$ Neoconstitucionalismo e Neoprocessualismo, cit., p. 219.

${ }^{35}$ Saber crítico e senso comum teórico dos juristas. Revista Sequencia - Estudos jurídicos e políticos. v. 3, n. 5, UFSC, Florianópolis: 1982, p. 56.

${ }^{36}$ Este princípio fora proposto por Chiovenda como consequência do princípio da concentração dos atos processuais, onde defendia a imposição de "reunião de todas as atividades processuais destinadas à instrução ou à marcha da causa em uma só audiência". In "Istituzioni di diritto processuale civile", v. I, Napoli, Jovne Editore, 1960, n.16, p. 45. Ver também fonte desse princípio em "Principii di diritto processuale civile", Napoli, Jovene, 1965 , pp. 682 a $689,707,708,1.100$ e 1.101. 
(ainda que se discorde de Chiovenda), bem como suas consequências daí advinda, como recurso e execução.

Cindido o processo e o julgamento há proceder duas sentenças na mesma relação jurídico-processual. Ora qual a razão para a negativa dessa atitude, se o réu parcialmente já admitiu?

Seguir os padrões tradicionais será uma incongruência constitucional, já que eles fazem com que a norma maior seja apenas simbólica e a lei ordinária apenas legislaçãoálibi. Esse tem sido o tratamento conferido pela doutrina, em sua maioria, e pelas decisões judiciais.

Como fazer então se a cultura jurídica acostumada está com o manejo dogmático tradicional de um processo uno e sentença una?

O próprio código de processo civil deixa exemplos de cisão do processo, dentre outros, o art. 475-O, $\S 3^{0},{ }^{37}$ formalizando autos complementares e autônomos, para hipótese de execução provisória. Algo também análogo no $§ 1^{\circ}$ do art. 899, ambos do CPC. ${ }^{38}$

Com a instauração desses autos paralelos, o vencido, caso queira, poderá recorrer mediante apelação, subindo ao Tribunal somente o caderno autônomo, permanecendo na marcha ordinária no juízo de origem, o processo com a parcela controvertida ensejadora da cognição plena.

Quanto à terceira indagação possível, mais uma vez não se pode desfazer do princípio constitucional da congruência provocando norma apenas simbólica, ao utilizar a decisão interlocutória (propriamente dita) para concessão da parte incontroversa a despeito de que os autos permaneceriam no juízo de origem e o A. I. distribuído diretamente no tribunal com cópias do art. 525, do CPC.

Em que pese o isolamento da questão pela não importância com nomenclatura que se dá ao ato do juiz, se sentença ou decisão interlocutória, o que importa é o tratamento jurídico que se dá a um e a outro instituto e suas consequências concretas.

Se se trata de algo incontroverso, somado ao comando constitucional da rápida solução do litígio, qual a razão - diante da parte incontroversa da demanda - de o juiz ter que novamente mencionar na sentença final acerca daquilo já decidido?

Pois, assim é a regra da tutela que se antecipa por meio de decisão interlocutória, como prevê o art. 520, inciso VII, do CPC.

37 Art. 475-O, § $3^{\circ}$ : “Ao requerer a execução provisória, o exequente instruirá a petição com cópias autenticadas das seguintes peças do processo, podendo o advogado declarar a autenticidade, sob sua responsabilidade pessoal: (...)"

38 Art. 899, § $1^{\circ}$ : "Alegada a insuficiência do depósito, poderá o réu levantar, desde logo, a quantia ou a coisa depositada, com a consequente liberação parcial do autor, prosseguindo o processo quanto à parcela controvertida". 
Portanto, a lei é clara, se parcela do litígio ou um dos pedidos cumulados torna, por atitude do réu, inquestionável, a essa partícula incontroversa deve-se um tratamento como qualquer outro, onde houver confissão, nos casos do efeito principal da revelia do art. 319 e a consequência do art. 330-II, com sentença de mérito definitiva e autônoma da parte controvertida.

A propósito, preleciona Teresa Arruda Alvim Wambier acerca da liberdade do juiz em conceder ou não medidas urgentes, aclarando a distância desse poder com a discricionariedade propriamente dita do agente público, para quem: “(...) Algumas observações devam ser feitas com o objetivo de diferenciar e afastar definitivamente essa liberdade, de que goza o Magistrado no ato de decidir, da liberdade com que pode contar o agente da Administração Pública em seu atuar". ${ }^{39}$

E, continua, no sentido de que "o modo como o assunto discricionariedade judicial vem sendo tratado e entendido por muitos tribunais brasileiro tem sido muitas vezes inadequado". ${ }^{40}$

Por fim, essa deve ser a interpretação que a norma exprime quanto ao fim social que enseja ao jurisdicionado, impondo ao magistrado a confirmação da incontrovérsia com a entrega do bem da vida [questionado] ao autor, não uma atividade de quererpoder do julgador, mas dever, usando as sábias palavras de Calamandrei, impõe, que o juiz deva ser guiado pelos critérios da razão e da experiência, que a sua consciência deva ser extraída da consciência jurídica e moral do povo a que pertence, não entendendo da forma que mais agrada, ou discricionariamente a um capricho. ${ }^{41}$

\subsection{CONSEQUÊNCIAS, PRÓS E CONTRA}

Da antecipação da tutela da parte incontroversa, por meio da decisão interlocutória e permanência nos mesmos autos e da forma que se propõe da cisão do processo e julgamento por sentença definitiva, têm-se os corolários, os quais pretende-se desenvolver a seguir

À decisão interlocutória [que conceder tutela antecipada provisória] cabe Agravo de Instrumento. Porém, impõe ao juiz confirmar na sentença final da demanda a concessão antecipada (art. 520, VII, CPC), e, assim o fazendo, ensejará recurso de

${ }^{39}$ Da liberdade do juiz na Concessão de liminares e a tutela antecipatória. In: WAMBIER, Teresa Arruda Alvim (Coord). Aspectos polêmicos da antecipação de tutela. $1^{\text {a }}$ edição. São Paulo: RT, 1997, P. 484.

40 Idem, p. 485.

${ }^{41}$ Piero Clamendrei. La genesi logica dela sentenza civile. In Opere Giuridiche, $\mathrm{Vol}^{\circ}{ }^{\circ}$, Nápoli, Morano Editore, 1965, p. 50. Em tradução livre, consta do texto original: "Ma non si deve credere [...] come più gli aggrada e che discrezionalità equivalga a capriccio; imperocchè in questo giudizio di opportunità e di equità il giudice deve essere guidato da quei criteri di ragione e di esperienza, che la sua coscienza deve attingere dalla coscienza giuridica e morale del popolo di cui egli fa parte". 
apelação. Disso decorre que da parte incontroversa conferida pelo Estado-juiz será objeto de dois recursos: primeiro o agravo de instrumento e, ao final, objeto de apelação com o todo.

Por esse prisma o tempo será bem maior [apenas em prol de uma execução provisória, que da mesma forma o autor não poderá ver satisfeito seu direito], pois se da parte incontroversa o juiz prolate sentença definitiva, deverá aguardar recurso em ambos os efeitos. A vantagem, nesse caso, é que em menos tempo torna esta parte julgada em definitivo, podendo executar definitivamente ipso fato.

Se provisória a decisão acerca da parcela incontroversa, sujeitará ao mesmo recurso (apelação) juntamente com a decisão da parte controvertida (no final do processo), todavia, bem mais tarde, não obstante a apelação da decisão que confirma a antecipação seja apenas no efeito devolutivo [novo inciso VII ao artigo 520, do CPC].

Sem prejuízo de que, sendo o recurso agravo de instrumento, corre o risco, dependendo do caso concreto, de o relator conceder efeito suspensivo (art. 527, III, CPC), em que defende Marinoni que "a eventual alegação de que esta decisão teria mais efetividade do que a decisão final tem pouco valor". ${ }^{42}$

Essa situação de birrecorribilidade ante a impossibilidade, em tese, da cisão (do processo e julgamento), nos afigura um contrassenso da interpretação doutrinária, entendendo incabível tal expediente (cisão do processo e julgamento), porém, permitindo dois recursos distintos para a decisão da mesma demanda in casu, da parte incontrovérsia: agravo e apelação.

Quando se fala em dois recursos distintos, significa (para quem defenda decisão interlocutória): agravo, quando da decisão interlocutória de concessão da tutela antecipada da parte incontroversa; e apelação, quando da confirmação (da antecipação) na sentença final juntamente com a parte controvertida, como referido supra.

Questiona-se: não se trata da razoável duração do processo? Como, então, atuar de forma que a autoridade constitucional permaneça apenas simbolicamente no sistema?

E, se estamos tratando de eliminação do fator tempo excessivamente desnecessário, impõe-se que sigamos o caminho em que o bem da vida possa ser desfrutado por seu titular no espaço de tempo mais curto e mais simples.

O ponto nevrálgico da questão é conferir o mais rápido possível, ou seja, o quanto antes, o bem da vida a quem tem direito, de forma definitiva quando essa questão onde não mais ser objeto de discussão em níveis recursais. ${ }^{43}$

Deflui daí que se é norma constitucional, as demais normas infra deverão estar em harmonia e, se o direito de alguém pronto para ser entregue, esbarrar em dogmas

${ }^{42}$ Luiz Guilherme Marinoni, "Tutela Antecipatória e Julgamento Antecipado - Parte Incontroversa da demanda", RT, 2002, p. 204.

${ }^{43}$ Diz-se aqui em níveis recursais, pois, resta, mesmo remotamente, a possibilidade da ação rescisória. 
e sistemas, ou se sujeitar a conflitos dentro do mesmo sistema, deve prevalecer o comando constitucional.

\section{CONCLUSÃO}

Defende-se, portanto, o modelo de tutela antecipada da parte incontroversa do litígio de forma real e concreta. Uma jurisdição singela, sem dogmas, sem complicações, conferindo - a partir da certeza da incontroversa - de imediato e definitivamente ao autor que tem razão. Que a práxis jurídica seja consecutiva e o ato do Estado-juiz um ato possível da definitividade - qual seja, a sentença de mérito.

Por consequência, seja a execução baseada em sentença definitiva impugnada por recurso de apelação mesmo com efeito suspensivo com base em cognição exauriente na qual não se olvida a execução [inicialmente] é apenas provisória, porém o importante é que, tornando a decisão definitiva [após os recursos] com força de coisa julgada material e desmembrada da outra parte controvertida, seguirá sua marcha normal, com o cumprimento da sentença.

Mesmo que a execução definitiva da sentença parcial seja após seu trânsito em julgado e isso ocorra após a decisão do Tribunal, tal definitividade será muito mais rápida e bem anterior, caso aguarde a definitividade após a decisão final da parte controvertida.

Conclamar a cultura jurídica para uma realidade efetivamente eficaz e, especificamente nos casos de incontrovérsia parcial do pedido ou da tutela de evidência, seja conferida de imediato tal pleito, pois o único elemento que possa barrar esse cumprimento in concreto na norma constitucional são os dogmas de um senso comum e uma crítica clássica, ortodoxa, que no dizer, ainda, de Luiz Warat aliena a ciência do direito, reduzindo-a a meros conceitos. ${ }^{44}$

\section{REFERÊNCIAS}

ARAUJO, Luiz Alberto David e NUNES JÚNIOR, Vidal Serrano. Curso de Direito Constitucional. 14. ed. São Paulo: Saraiva, 2010.

BEDAQUE, José Roberto dos Santos. Efetividade do processo e técnica processual. São Paulo: Malheiros, 2006.

CALAMANDREI, Piero. La genesi logica dela sentenza civile. Opere Giuridiche, v.1. Nápoli: Morano Editore, 1965.

CAMBI, Eduardo. Neoconstitucionalismo e Neoprocessualismo - direitos fundamentais, políticas públicas e protagonismo judiciário. 2. ed. rev. e atualizada. São Paulo: Editora Revista dos Tribunais, 2011.

${ }^{44}$ In: Saber crítico e senso comum teórico dos juristas. Revista Sequencia - Estudos jurídicos e políticos, cit., pp. 49-50. 
CARNELUTTI, Francesco. Sistema de Direcho Procesal Civil. v.1. Tradução ao Espanhol de Niceto Alcalá-Zamora y Castilho e Santiago Sentís Melendo. Buenos Aires: Uteha Argentina, 1944. . Instituições do Processo Civil. Campinas: Classic Book, v 1.

COUTURE, Eduardo J. Estudios de derecho processal civil - La constitución y el proceso civil. Tomo I. Ediar, Soc. Anón Editores: Buenos Aires, 1948.

GOLDSCHMIDT, Werner. La ciencia de la justicia (Dikelogia). Madrid: Editora Aguilar, 1958.

KOEHLER, Frederico Augusto Leopoldino. A razoável duração do processo. Salvador: Editora Jus Podivm, 2009.

MARINONI, Luiz Guilherme. Tutela Antecipatória e Julgamento Antecipado - Parte Incontroversa da demanda. São Paulo: Editora Revista dos tribunais, 2002.

NEVES, Celso. Constitucionalização Simbólica. 3. ed. São Paulo: Martins Fontes, 2011.

NIGRO, Casimiro. PROSPERI, Luigi. L'irragionevole durata dei processi - Cause e rimedi per la violazione del direito dalla giustizia. Forlì: Experta Edizioni, 2009.

OLIVEIRA, Carlos Alberto Álvaro de. Do formalismo no processo civil - Proposta de um formalismovalorativo. 4. ed. rev., atual. e aumentada. São Paulo: Editora Saraiva, 2010.

RAGAZZI, José Luiz. Tutela antecipada nas relações de consumo. São Paulo, Editora Juarez de Oliveira, 2002.

ROCHA, Cesar Asfor. A luta pela efetividade da jurisdição. São Paulo: Editora Revista dos Tribunais, 2007.

TUCCI, José Rogério Cruz. Duração Razoável do Processo. In: JAIME, Fernando Gonzaga; FARIA, Juliana Cordeiro de; LAUAR, Maria Terra (Coords.). Processo Civil - Novas Tendências: Homenagem ao professor Humberto Theodoro Junior. Belo Horizonte: Editora Del Rey, 2008.

. Direito processual civil europeu contemporâneo. In: CORRÊA, Fábio Peixinho Gomes [et al.]; TUCCI, José Rogério Cruz (Coord.). São Paulo: Lex Editora, 2010.

TOMMASEO, Ferruccio. Lezioni di diritto processuale civile. v. I, Padova: Cedam, 2002. 2002 .

. I Provvedimenti D’urgenza - Strutura e limiti dela tutela anticipatoria. Padova: Cedam,

WAMBIER, Teresa Arruda Alvim. Da liberdade do juiz na Concessão de liminares e a tutela antecipatória. In: WAMBIER, Teresa Arruda Alvim (Coord.). Aspectos polêmicos da antecipação de tutela. São Paulo: Revista dos Tribunais, 1997.

WARAT, Luiz Alberto. Saber crítico e senso comum teórico dos juristas. Revista Sequencia Estudos jurídicos e políticos. v. 3, n. 5. UFSC, Florianópolis, 1982. 